\title{
Performance Enhancement by Unsteady-State Reactor Operation: Theoretical Analysis for Two-Sites Kinetic Model
}

\author{
By S. I. Reshetnikov, E. A. Ivanov, L. Kiwi-Minsker, and A. Renken*
}

Theoretical analysis of the reactor performance under unsteady-state conditions was carried out. The reactions are described by two kinetic models, which involve the participation in catalytic reaction of two types of active sites. The kinetic model I assumes the blocking of one of the active sites by a reactant, and the kinetic model II suggests a transformation of active sites of one type into another under the influence of the reaction temperature. The unsteady-state conditions on the catalyst surface are supposed to be created (i) by forced oscillations of temperature and concentration in the reactor inlet (periodic operation of reactor) and (ii) by catalyst circulation between two reactors in a dual-reactor system (spatial regulation). The influence of various parameters like concentration of reactant, cycle split, length of period of forced oscillations, temperatures and the ratio of catalyst volumes in the dual-reactor was investigated with respect to the yield of the desired product. It is shown that for both cases of unsteady-state conditions (periodic reactor operation as well as in a dual-reactor system), a mean reaction rate predicted by the kinetic model I was up to two times higher than the steady-state value. The kinetic model II shows a $20 \%$ increase of the selectivity towards the desired product.

\section{Introduction}

Experimental and theoretical studies in heterogeneous catalysis during the last decades have given evidence that reactor performance under unsteady-state conditions can lead to improved process efficiency compared to steady-state operation. Under transient conditions it is possible to maintain the catalyst surface in an optimal state increasing the mean reaction rate and selectivity towards a specific product resulting in an enhanced reactor performance.

The catalyst unsteady state can be attained in two ways:

- by forced oscillations of the reactant concentrations or flow reversal (regulation by periodic reactor operations) [1-7].

- by spatial regulation, when input and output parameters of the reactor do not change with time, but the catalyst moves in a field of variable reactant concentrations and/or temperature either in a fluidized bed or in a dual-reactor system $[8,9]$.

There have been a number of theoretical attempts to model reaction schemes and to distinguish classes of chemical reactions, for which the increased efficiency under unsteadystate conditions can be predicted [2,10-13]. These studies were devoted to the analysis and optimization of regimes under periodic operations, or optimization of regimes in a dualreactor system with fluidized-bed reactors. Direct comparison of the reaction efficiency described by the same kinetic scheme operated periodically or in a dual-reactor system has not been studied and reported up to now. This information is important in order to make a proper choice between different methods to attain an unsteady state in regard to the reaction kinetics.

[*] A. Renken (author to whom correspondence should be addressed), L. Kiwi-Minsker, Laboratory of Chemical Reaction Engineering, Swiss Federal Institute of Technology (EPFL), CH-1015 Lausanne, Switzerland; S. I. Reshetnikov, E. A. Ivanov, Boreskov Institute of Catalysis SB RAS, Pr.Akad. Lavrentieva 5, Novosibirsk 630090, Russia.
The present work is aimed on the comparative study of the reaction efficiency under unsteady-state conditions created via (i) periodic reactor operation and (ii) spatial regulation in a dual-reactor system.

\section{Description of the Kinetic Models}

Both reaction kinetic models are based on the assumption of two types of active sites, $S_{1}$ and $S_{2}$, on the catalytic surface involved in the reaction.

The first model (Model I) was proposed to explain the so called "Stop-Effect" first observed experimentally by Koubek et al. [14] for the deamination of amines and the dehydration of alcohols to alkenes on amphoteric metal oxide catalysts like alumina. When the reactant flow entering the reactor is abruptly replaced by an inert gas, the rate of the alkene formation immediately increases, reaches a maximum, and finally decreases to zero. To describe the experimental observations, it is assumed that two types of catalytically active sites are involved in the dehydration reaction. The reactant (A) is adsorbed on sites $S_{1}$ and $S_{2}$ to form the species $\mathrm{AS}_{1}$ and $\mathrm{AS}_{2}$. In a consecutive step $\mathrm{AS}_{1}$ interacts with a free site $S_{2}$ to produce the alkene and water. In consequence, adsorption on $\mathrm{S}_{2}$ diminishes the concentration of free sites and inhibits the formation of alkenes. The adsorption and desorption processes on site $\mathrm{S}_{2}$ are assumed to be fast. Therefore, the reactant desorbs quickly after switching the feed to inert gas, liberating type 2 sites. This leads to an increase of $S_{2}$ concentration and of the rate of alkene formation $^{1)}$.

1) List of symbols at the end of the paper. 
Model I

Kinetic functions

$\mathrm{A}+\mathrm{S}_{1} \underset{\mathrm{k}_{-1}}{\stackrel{\mathrm{k}_{1}}{\longrightarrow}} \mathrm{AS}_{1}$

$\mathrm{A}+\mathrm{S}_{2} \underset{\mathrm{k}_{-2}}{\stackrel{\mathrm{k}_{2}}{\rightleftarrows}} \mathrm{AS}_{2}$

$\mathrm{AS}_{1}+\mathrm{S}_{2} \stackrel{\mathrm{k}_{3}}{\longrightarrow \mathrm{B}}+\mathrm{C}+\mathrm{S}_{1}+\mathrm{S}_{2}$

$\mathrm{r}_{1}=\mathrm{k}_{1} \mathrm{C}_{\mathrm{A}}\left(1-\theta_{1}\right)$

$\mathrm{r}_{2}=\mathrm{k}_{2} \mathrm{C}_{\mathrm{A}}\left(1-\theta_{2}\right)-\mathrm{k}_{-2} \theta_{2}$

$\mathrm{r}_{3}=\mathrm{k}_{3} \theta_{1}\left(1-\theta_{2}\right)$

In theoretical studies Thullie and Renken $[15,16]$ demonstrated the beneficial effect of forced concentration oscillations on the reactor performance. The theoretical results were confirmed experimentally for the dehydration of alcohols by $[5,6]$.

The second model (Model II) assumes that the reaction takes place through two parallel pathways, which involve $S_{1}$ and $\mathrm{S}_{2}$ active sites.

\section{Model II}

$\mathrm{A}+\mathrm{S}_{1} \stackrel{\mathrm{k}_{1}}{\longrightarrow} \mathrm{B}+\mathrm{S}_{1}$

$\mathrm{A}+\mathrm{S}_{2} \stackrel{\mathrm{k}_{2}}{\longrightarrow} \mathrm{C}+\mathrm{S}_{2}$

$\mathrm{S}_{1} \underset{\mathrm{k}_{4}}{\stackrel{\mathrm{k}_{3}}{\rightleftarrows}} \mathrm{S}_{2}$

In this case the model suggests a transformation of the site $S_{1}$ into the site $S_{2}$. The equilibrium constant of this transformation depends on temperature. At low temperature type $S_{1}$ predominates on the surface and at high temperature the type $S_{2}$. Temperature controls the catalyst surface composition and consequently the reaction selectivity, since different products ( $\mathrm{B}$ or $\mathrm{C}$ ) are formed on the different active sites $S_{1}$ or $S_{2}$. It is important to note that the desired product is $\mathrm{B}$, thus, the selectivity to $\mathrm{B}$ is the most important parameter to increase. A similar kinetic model including two types of active sites, which transform one into another depending on the temperature, was used to describe the partial oxidation of oxylene to phthalic anhydride as the desired product B [17].

Based on the two models the influence of various parameters, like temperature, concentration of reactants, period of forced oscillations, etc. on the reaction rate, and selectivity was studied. The parameters in both models were chosen in a way that the corresponding relaxation times are approximately equal.

\section{Modeling on the Base of the Kinetic Model I.}

\subsection{Forced Concentration Oscillations}

The reactant concentration in the reactor feed is periodically varied in the form of a square wave function as presented in Fig. 1. In the first part of a period the concentration corresponds to $\mathrm{C}_{\mathrm{A}}$ and falls to zero in the second part of a period. The split between the two parts of a period is defined by the parameter $\gamma$. For $\gamma=0$ the reactor is operated under steady-state with a constant feed concentration, $\mathrm{C}_{\mathrm{A}}$. No reactant is supplied for $\gamma=1\left(\mathrm{C}_{\mathrm{A}}=0\right)$.

For a differential reactor, the overall production rate of $\mathrm{B}$ is given by Eq. (3):
$\mathrm{R}_{\mathrm{B}}=\mathrm{r}_{3}=\mathrm{k}_{3} \theta_{1}\left(1-\theta_{2}\right)$

The dynamic behavior of the reactant adsorbed on the surface can be described as:

$\frac{\mathrm{d} \theta_{1}}{\mathrm{dt}}=\mathrm{r}_{1}-\mathrm{r}_{3}, \quad t=0: \quad \theta_{1}=\theta_{10}$.

or

$\frac{d \theta_{1}}{d t}=\mathrm{k}_{1} \mathrm{C}_{\mathrm{A}}\left(1-\theta_{1}\right)-\mathrm{k}_{3} \theta_{1}\left(1-\theta_{2}\right), t=0 ; \quad \theta_{1}=\theta_{10}$

Instantaneous equilibrium is assumed for the adsorption of A on the sites $S_{2}$, and adsorption on $S_{1}$ is supposed to be irreversible. The dimensionless steady-state concentration of $\mathrm{AS}_{2}\left(\theta_{2 \mathrm{~s}}\right)$ is given by

$\theta_{2 \mathrm{~s}}=\frac{\mathrm{K}_{2} \mathrm{C}_{\mathrm{A}}}{\mathrm{K}_{2} \mathrm{C}_{\mathrm{A}}+1}$

with $\mathrm{K}_{2}=\mathrm{k}_{2} / \mathrm{k}_{-2}$

Under steady-state conditions $\left(\frac{\mathrm{d} \theta_{1}}{\mathrm{dt}}=0\right)$ the surface concentration of $\mathrm{AS}_{1}$ can be easily calculated:

$\theta_{1 \mathrm{~s}}=\frac{\mathrm{k}_{1} \mathrm{C}_{\mathrm{A}}}{\mathrm{k}_{1} \mathrm{C}_{\mathrm{A}}+\frac{\mathrm{k}_{3}}{\mathrm{~K}_{2} \mathrm{C}_{\mathrm{A}}+1}}$

Fig. 2 shows the surface concentrations $\theta_{1 \mathrm{~s}}, \theta_{2 \mathrm{~s}}$ and steadystate reaction rate $R_{B s}$ as a function of the gas phase concentration of reactant $\mathrm{A}$ for the set of parameters listed in Tab. 1.

Under steady-state conditions the production rate increases with increasing reactant concentration $\mathrm{C}_{\mathrm{A}}$ up to a maximum value. A further concentration increase leads to a decrease of the reaction rate due to the blocking of free $\mathrm{S}_{2}$.

By introducing the relaxation time $\tau_{R}$ :

$\tau_{R}=\frac{1}{\mathrm{k}_{1} \mathrm{C}_{\mathrm{A}}+\frac{\mathrm{k}_{3}}{\mathrm{~K}_{2} \mathrm{C}_{\mathrm{A}}+1}}$

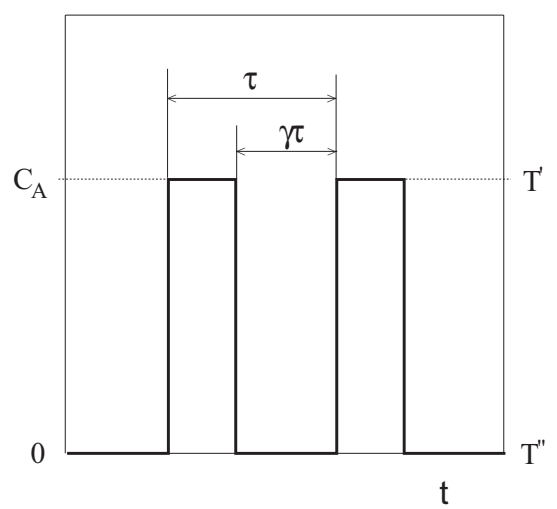

Figure 1. Schematic presentation of a reagent concentration or/and temperature variation in a reactor. 


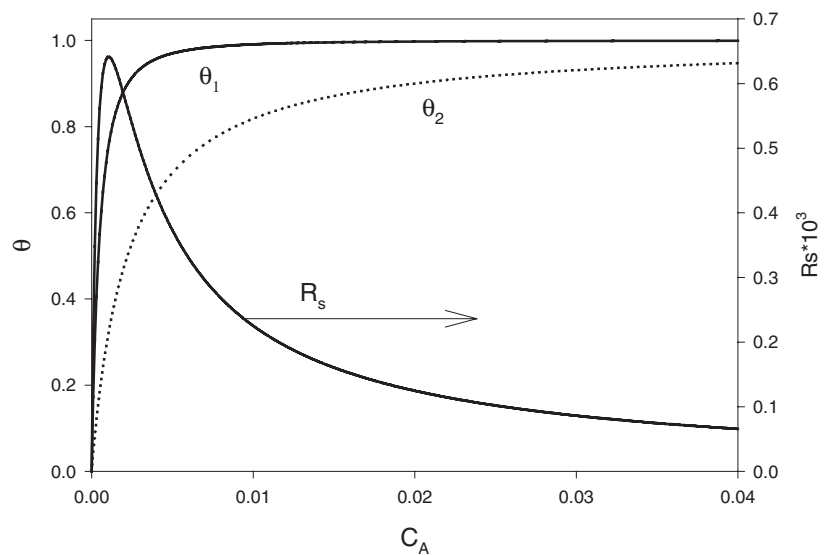

Figure 2. Steady-state reaction rate $\left(\mathrm{R}_{\mathrm{S}}\right)$ and concentration of active sites $\left(\theta_{1}\right.$, $\left.\theta_{2}\right)$ vs. concentration of reactant A; Model I

Table 1. Parameters of kinetic model $I$.

\begin{tabular}{|l|l|}
\hline $\mathrm{k}_{1}$ & $2.5 \mathrm{~s}^{-1}$ \\
\hline $\mathrm{K}_{2}$ & 450 \\
\hline $\mathrm{k}_{3}$ & $1.25 \cdot 10^{-3} \mathrm{~s}^{-1}$ \\
\hline
\end{tabular}

Eq. (4) can be rewritten as follows:

$\tau_{\mathrm{R}} \frac{\mathrm{d} \theta_{1}}{\mathrm{dt}}=\theta_{1 \mathrm{~s}}-\theta_{1}$

$\mathrm{t}=0: \quad \theta_{1}=\theta_{10}$

Integration of Eq. (8) allows to determine the surface concentration under transient conditions after a stepwise change of the gas concentration:

$\theta_{1}(t)=\theta_{1 s}+\left(\theta_{10}-\theta_{1 s}\right) \exp \left(-\frac{t}{\tau_{R}}\right)$

A periodic stop of the reactant feed can result in a considerable increase of the total yield of the product and the average reactor performance. For a given set of kinetic parameters the performance under periodic concentration variations depends on the mean feed concentration, the length of the period $\tau$ and the cycle split $\gamma$.

The average reaction rate within the first $\left(\overline{\mathrm{R}}^{\prime}\right)$ and second part of the period $\left(\overline{\mathrm{R}}^{\prime \prime}\right)$ is given by:

$\overline{\mathrm{R}}^{\prime}=\frac{1}{(1-\gamma) \tau} \int_{0}^{(1-\gamma) \tau} \mathrm{R}(\mathrm{t}) \mathrm{dt}, \mathrm{C}_{\mathrm{A}}>0$

$\overline{\mathrm{R}}^{\prime \prime}=\frac{1}{\gamma \tau} \int_{(1-\gamma) \tau}^{\tau} \mathrm{R}(\mathrm{t}) \mathrm{dt}, \mathrm{C}_{\mathrm{A}}=0$

After substituting the instantaneous reaction rate $\mathrm{R}(\mathrm{t})$ from Eq.(6) and subsequent integration, the mean rate can be calculated with Eqs. (12) and (13)

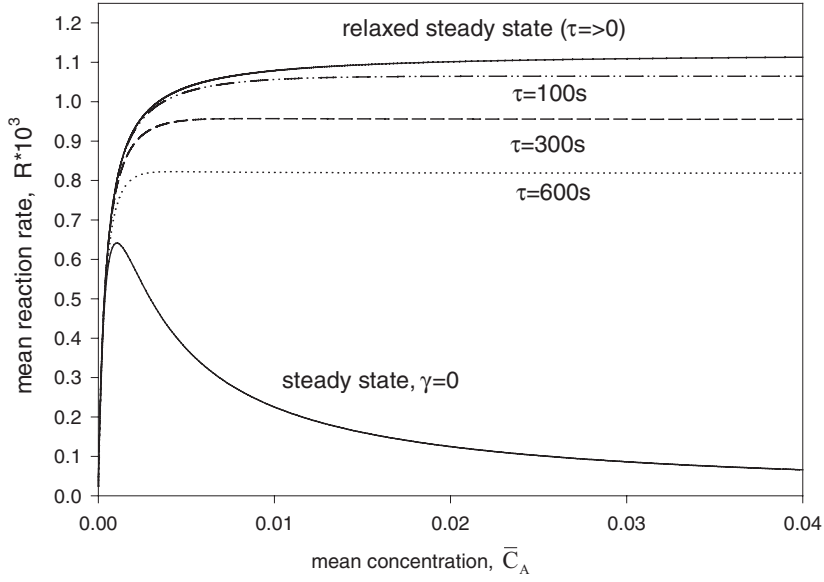

Figure 3. Mean reaction rate over a period as function of the mean feed concentration for different length of period and a cycle split of $\gamma=0.9 ;$ Model I.

$$
\begin{aligned}
& \overline{\mathrm{R}}^{\prime}=\frac{\mathrm{k}_{3}}{\left(\mathrm{~K}_{2} \mathrm{C}_{\mathrm{A}}+1\right)(1-\gamma) \tau} \\
& \left\{\theta_{1 \mathrm{~s}}^{\prime} \tau(1-\gamma)+\tau_{\mathrm{R}}^{\prime}\left(\theta_{10}^{\prime}-\theta_{1 \mathrm{~s}}^{\prime}\right)\left[1-\exp \left(\frac{(\gamma-1) \tau}{\tau_{\mathrm{R}}^{\prime}}\right)\right]\right\} \\
& \overline{\mathrm{R}}^{\prime \prime}=\frac{\mathrm{k}_{3}}{\gamma \tau}\left\{\theta_{1 \mathrm{~s}}^{\prime \prime} \gamma \tau+\tau_{\mathrm{R}}^{\prime \prime}\left(\theta_{10}^{\prime \prime}-\theta_{1 \mathrm{~S}}^{\prime \prime}\right)\left[1-\exp \left(-\frac{\gamma \tau}{\tau_{\mathrm{R}}^{\prime \prime}}\right)\right]\right\}
\end{aligned}
$$

with the boundary conditions for the $n$th period:

$\left(\theta_{10}^{\prime}=\theta_{1}^{\prime \prime}\right)($ at $\mathrm{t}=\gamma \tau)$ and $\left(\theta_{10}^{\prime \prime}=\theta_{1}^{\prime}\right)($ at $\mathrm{t}=(1-\gamma) \tau)$

Superscripts (') and (") correspond to the first and the second part of period respectively.

The overall reaction rate during a period is

$\overline{\mathrm{R}}=\overline{\mathrm{R}}^{\prime}(1-\gamma)+\overline{\mathrm{R}}^{\prime \prime} \gamma$

When the forced cycling is repeated sufficiently often, the results within the periods become identical. For these cycle invariant conditions the mean production rate as a function of the reactant concentration and length of period is shown in Fig. 3 for a constant cycle split of $\gamma=0.9$. The mean reaction rates are considerably higher compared to the maximum at steady-state for concentrations exceeding the optimal steady-state value.

As instantaneous adsorption equilibrium for sites 2 is assumed, a maximal average reaction rate is obtained for the length of a period approaching zero $(\tau==>0)$. The optimal cycle split depends on the length of period demonstrated by Thullie and Renken [15].

\subsection{Spatial Regulation of the Unsteady State of the Catalyst by a Dual-Reactor System}

The schematic diagram of a dual-reactor system is presented in Fig. 4. The reactant is fed continuously to reactor one, in 


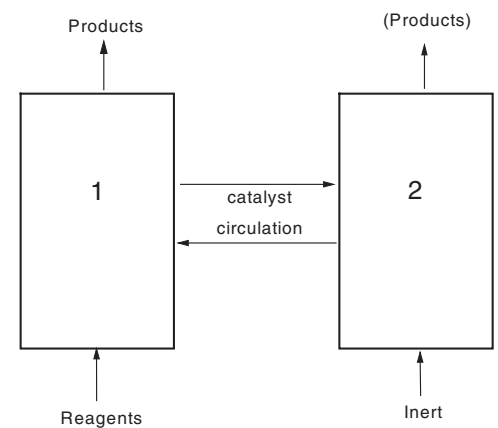

Figure 4. Schematic diagram of a dual-reactor system with a catalyst circulation.

parallel only inert gas passes through the second reactor. The temperatures are identical $\left(\mathrm{T}^{\prime}=\mathrm{T}^{\prime \prime}\right)$. The catalyst circulates between the two reactors with a circulation rate of

$\mathrm{u}_{\mathrm{c}}=\frac{\mathrm{Q}}{\mathrm{V}_{1}+\mathrm{V}_{2}}$

$\mathrm{V}_{1}$ and $\mathrm{V}_{2}$ are the volumes occupied by the catalyst in reactor one and two, Q corresponds to the volumetric flow rate of the catalyst, and the volumetric fraction of the first reactor is given by

$\alpha^{\prime}=\frac{V_{1}}{V_{1}+V_{2}}$

Perfect gas and solid mixing is assumed in both reactors. Under steady-state conditions the following mass balances for the system are obtained:

$\mathrm{C}_{\mathrm{A}}^{\mathrm{o}}-\mathrm{C}_{\mathrm{A}}+\mathrm{a} \tau^{\prime}\left[\mathrm{k}_{2} \theta_{2}^{\prime}-\mathrm{k}_{1} \mathrm{C}_{\mathrm{A}}\left(1-\theta_{1}^{\prime}\right)-\mathrm{k}_{2} \mathrm{C}_{\mathrm{A}}\left(1-\theta_{2}^{\prime}\right)\right]=0$

$\mathrm{u}_{\mathrm{c}}\left(\theta_{1}^{\prime \prime}-\theta_{1}^{\prime}\right)+\alpha^{\prime}\left[\mathrm{k}_{1} \mathrm{C}_{\mathrm{A}}\left(1-\theta_{1}^{\prime}\right)-\mathrm{k}_{3} \theta_{1}^{\prime}\left(1-\theta_{2}^{\prime}\right)\right]=0$

$\mathrm{u}_{\mathrm{c}}\left(\theta_{2}^{\prime \prime}-\theta_{2}^{\prime}\right)+\alpha^{\prime}\left[\mathrm{k}_{2} \mathrm{C}_{\mathrm{A}}\left(1-\theta_{2}^{\prime}\right)-\mathrm{k}_{-2} \theta_{2}^{\prime}\right]=0$

$\mathrm{u}_{\mathrm{c}}\left(\theta_{1}^{\prime}-\theta_{1}^{\prime \prime}\right)-\left(1-\alpha^{\prime}\right) \mathrm{k}_{3} \theta_{1}^{\prime \prime}\left(1-\theta_{2}^{\prime \prime}\right)=0$

$\mathrm{u}_{\mathrm{c}}\left(\theta_{2}^{\prime}-\theta_{2}^{\prime \prime}\right)-\left(1-\alpha^{\prime}\right) \mathrm{k}_{-2} \theta_{2}^{\prime \prime}=0$

If we assume differential conversion of the reactant, inlet and outlet concentrations are identical $\left(\mathrm{C}_{\mathrm{A}} \cong \mathrm{C}_{\mathrm{A}, 0}\right)$, and the production rates in the two reactors are given by

$\mathrm{R}_{\mathrm{B}}=\alpha^{\prime} \mathrm{k}_{3} \theta_{1}^{\prime}\left(1-\theta_{2}^{\prime}\right)+\left(1-\alpha^{\prime}\right) \mathrm{k}_{3} \theta_{1}^{\prime \prime}\left(1-\theta_{2}^{\prime \prime}\right)$

In Fig. 5 the mean reaction rate in the dual-reactor system as a function of the reactant concentration $\mathrm{C}_{\mathrm{A}}$ is compared to the performance of a single reactor $\left(\alpha^{\prime}=1\right)$. In contrast to a single reactor, the production rate in the dual system with $0.4>\alpha^{\prime} \geq$ 0.05 increases with increasing reactant concentrations and approaches a maximum value. As the sorption processes on sites $S_{2}$ are supposed to be fast, these sites are quickly liberated

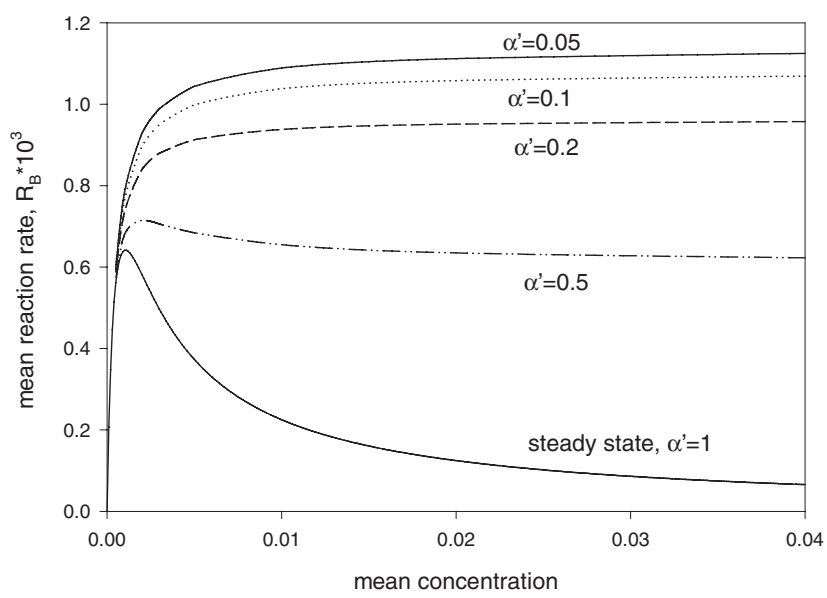

Figure 5. Mean reaction rate in the dual system as a function of the mean feed concentration for different ratios of catalyst volume Model I. $\mathrm{u}_{\mathrm{c}}=100 \mathrm{~h}^{-1}$.

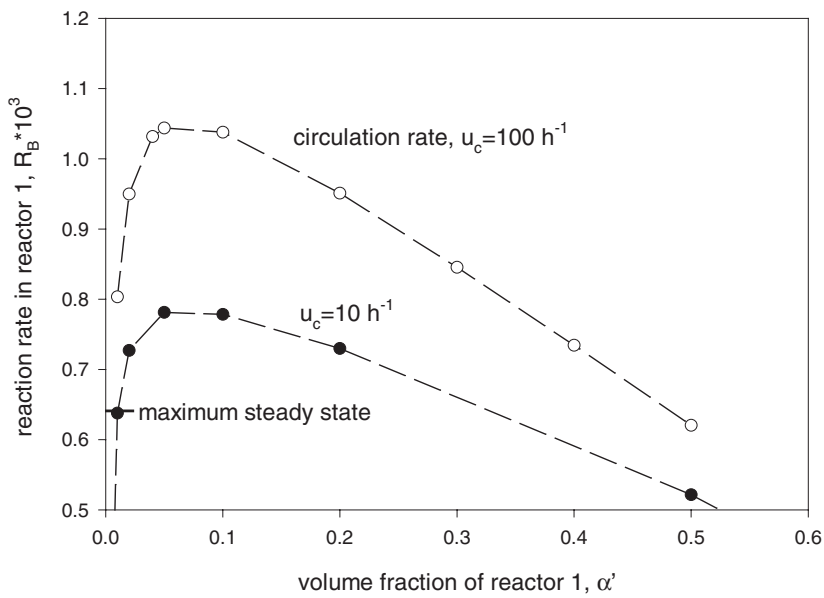

Figure 6. Mean reaction rate in the dual system as function of the ratio of catalyst volume and catalyst circulation rate. Mean inlet concentration $\mathrm{C}_{\mathrm{A}}=0.1 ;$ Model I

in the inert atmosphere resulting in a high production rate. In consequence a big volume of reactor $2\left(\operatorname{small} \alpha^{\prime}\right)$ is favorable. This is demonstrated in Fig. 6, where the production rate as function of the volume fraction $\alpha^{\prime}$ is shown for two different circulation rates. For $\alpha^{\prime}=0$ only inert gas is fed through the whole volume and no product is formed. For $\alpha^{\prime}=1$ a single reactor is operating at the high reactant concentrations and the resulting reaction rate is low compared to maximum obtainable under steady-state conditions. Depending on the chosen operating parameters the performance of the system passes through a maximum value. Compared to a single reactor operated at optimal conditions, the performance can be nearly doubled in the proposed dual system.

\section{Modeling on the Base of the Kinetic Model II.}

\subsection{Forced Oscillations of Temperature and Concentration}

The feed concentration to the differential reactor is varied in form of a square wave function between $\mathrm{C}_{\mathrm{A}}$ and zero. 
Simultaneously, the reactor temperature is changed between $\mathrm{T}^{\prime}$ and $\mathrm{T}^{\prime \prime}$ as indicated in Fig. 1. The dynamic behavior of surface sites $S_{1}(\theta)$ after a stepwise change of the temperature can be described by the following equation:

$\frac{\mathrm{d} \theta}{\mathrm{dt}}=-\mathrm{r}_{3}=\mathrm{k}_{4}(1-\theta)-\mathrm{k}_{3} \theta$

$\mathrm{t}=0: \theta=\theta_{0}$

After integration we obtain an expression for the surface concentration of sites $\mathrm{S}_{1}$ :

$\theta(\mathrm{t})=\theta_{\mathrm{S}}+\left(\theta_{0}-\theta_{\mathrm{S}}\right) \exp \left(-\frac{t}{\tau_{R}}\right)$

with the relaxation time

$\tau_{\mathrm{R}}=\frac{1}{\mathrm{k}_{3}+\mathrm{k}_{4}}$

For the steady-state concentration it follows:

$\theta_{\mathrm{S}}=\frac{1}{1+\mathrm{k}_{3} / \mathrm{k}_{4}}$

As already mentioned above, the parameter for optimization is the selectivity $S_{B}$. The instantaneous selectivity towards the desired product $\mathrm{B}$ is defined as the ratio of its production rate to the transformation rate of the reactant $\mathrm{A}$ :

$\mathrm{S}_{\mathrm{B}}=\frac{\mathrm{r}_{1}}{\mathrm{r}_{1}+\mathrm{r}_{2}}=\frac{1}{1+\frac{\mathrm{k}_{2}}{\mathrm{k}_{1}}\left(\frac{1}{\theta}-1\right)}$

After substituting $\theta_{\mathrm{s}}$ in Eq. (28) we obtain the following equation for the steady-state selectivity:

$\mathrm{S}_{\mathrm{B}, \mathrm{s}}=\left(1+\frac{\mathrm{k}_{2}(\mathrm{~T}) \mathrm{k}_{3}(\mathrm{~T})}{\mathrm{k}_{1}(\mathrm{~T}) \mathrm{k}_{4}(\mathrm{~T})}\right)^{-1}$

Under steady-state conditions, the selectivity is independent on the reactant concentrations and on the reaction temperature for $E_{2}+E_{3}-E_{1}-E_{4}=0$, if the temperature dependence of the rate constants can be described by the Arrhenius equation. For the kinetic parameters shown in Tab. 2 a selectivity of $\mathrm{S}_{\mathrm{B}, \mathrm{s}}=0.667$ is obtained. This value is independent of reaction conditions at steady state.

By substituting Eq. (25) in (28) the following relationship is obtained allowing the prediction of the instantaneous selectivity under transient conditions after a stepwise change of the reaction temperature:

$\mathrm{S}_{\mathrm{B}}(\mathrm{t})=\frac{\theta_{\mathrm{s}} \exp \left(\mathrm{t} / \tau_{\mathrm{R}}\right)+\left(\theta_{0}-\theta_{\mathrm{s}}\right)}{\left[\kappa\left(1-\theta_{\mathrm{s}}\right)+\theta_{\mathrm{s}}\right] \exp \left(\mathrm{t} / \tau_{\mathrm{R}}\right)+\left(1-\theta_{\mathrm{s}}\right)(1-\kappa)}$

with $\kappa=\mathrm{k}_{2} / \mathrm{k}_{1}$

Fig. 7 shows responses of the surface concentration of sites $\mathrm{S}_{1}, \theta$, and the selectivity after an abrupt increase of the temperature from $\mathrm{T}^{\prime \prime}$ to $\mathrm{T}^{\prime}$ over a time interval of $10 \mathrm{~min}$. After this time the temperature is changed back to $T^{\prime \prime}$. At low temperatures the concentration of site $\mathrm{S}_{1}$ is high. Therefore,
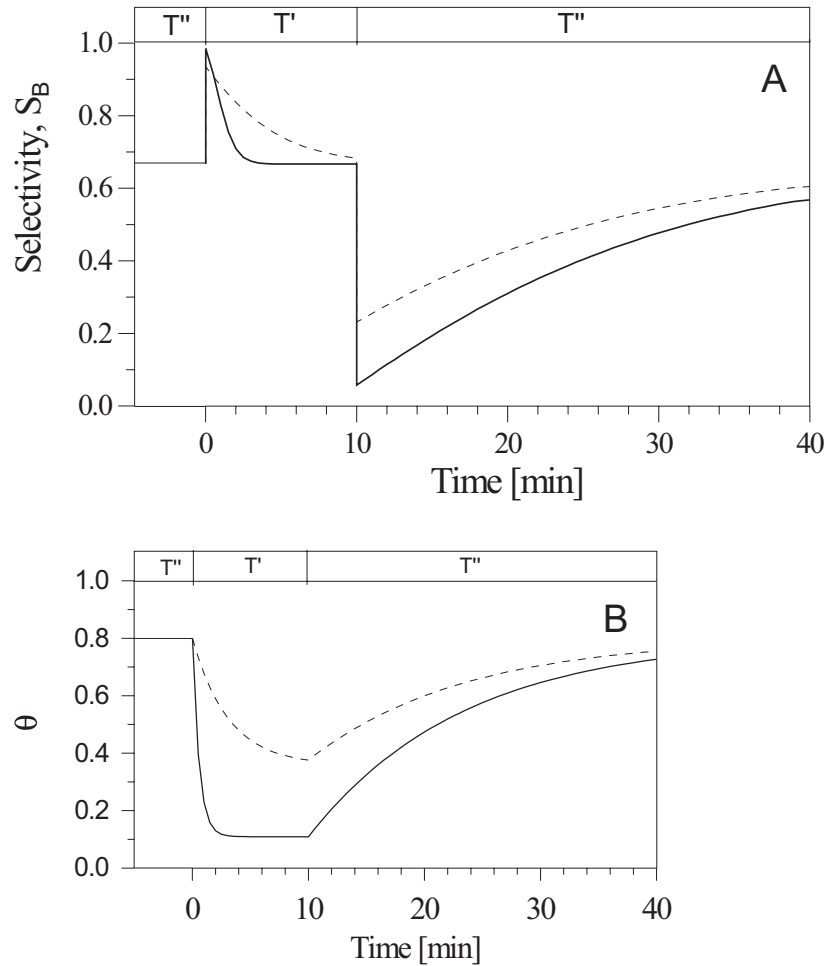

Figure 7. Transient selectivity (A) and the concentrations of active sites (B) during temperature changing at $\mathrm{C}_{\mathrm{A}}>0 ;$ Model II. Solid line: $\mathrm{T}^{\prime}=650 \mathrm{~K}, \mathrm{~T}^{\prime \prime}=500$ $\mathrm{K}$; dashed line: $\mathrm{T}^{\prime}=575 \mathrm{~K}, \mathrm{~T}^{\prime \prime}=500 \mathrm{~K}$

the sudden increase of temperature results first in a steep increase of the production rate of the target product (B), and the instantaneous selectivity jumps from initially $66.7 \%$ to $98.7 \%$ for $\mathrm{T}^{\prime}=650 \mathrm{~K}$. At the same time $\mathrm{S}_{1}$ sites are transformed to $S_{2}$ species leading to diminished product selectivity. By decreasing the reaction temperature the $S_{2}$ sites are re-transformed to $S_{1}$. The rate of the sites transformations and consequently the length of the transient period depends on the relaxation time $\tau_{\mathrm{R}}$, which is shorter at high temperatures. As a consequence, the time needed to recover the high initial $S_{1}$ concentration at $T^{\prime \prime}$ is longer compared to the first period.

After a switch from $T^{\prime}==>T^{\prime \prime}$ the resulting low temperature is disadvantageous for the product formation and the selectivity is quite low. To get an overall high selectivity for the target product, the reactant feed has to be stopped at low temperatures as indicated on Fig. 1.

To get the mean selectivity under periodic operation Eq. (30) was integrated over the first part of the period $[0,(1-\gamma) \tau]$ :

$\bar{S}_{B}=\frac{\tau_{R}^{\prime}}{(1-\gamma) \tau}\left(\frac{\theta_{s}}{L}-\frac{\theta_{0}-\theta_{s}}{M}\right) \ln \frac{\kappa \exp \left(\frac{(1-\gamma) \tau}{\tau_{R}^{\prime}}\right)+M}{L+M}+\frac{\theta_{0}-\theta_{s}}{M}$

with $\mathrm{L}=\mathrm{k}_{2} / \mathrm{k}_{1}\left(1-\theta_{\mathrm{s}}\right)+\theta_{\mathrm{s}} ; \mathrm{M}=\left(\theta_{0}-\theta_{\mathrm{s}}\right)\left(1-\mathrm{k}_{2} / \mathrm{k}_{1}\right)$.

When the forced temperature cycling is repeated sufficiently often, the results within the periods become identical and the mean selectivity under periodic operation is obtained. In Fig. 8 the average selectivity as a function of period split for 


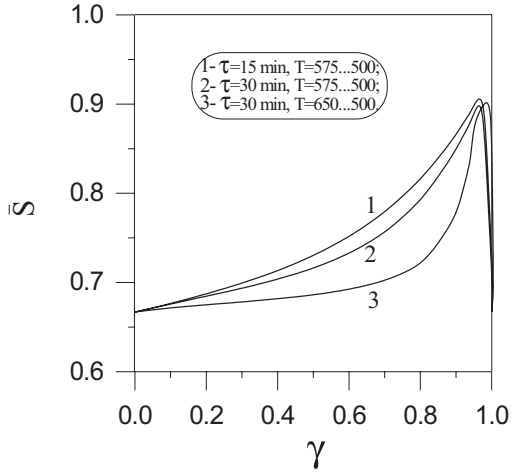

Figure 8. Averaged selectivity during the first part of a period as a function of a cycle split $(\gamma)$; Model II.

different cycle times and temperature is shown. For $\gamma \rightarrow 0$ and $\gamma \rightarrow 1$ the selectivity tends to the steady-state value of $66.7 \%$. Starting at $\gamma=0$ the selectivity increases with increasing period split to a maximal value of $90 \%$ at $\gamma \approx 0.95$ and finally falls very steep to the steady-state value at $\gamma=1$. In summary, under periodic operation a $24 \%$ selectivity increase compared to steady-state is predicted for the parameter set shown in Tab. 2.

Table 2. Parameters of kinetic model II.

\begin{tabular}{|l|l|l|}
\hline$i$ & $\mathrm{k}_{\mathrm{i}}(500 \mathrm{~K}), \mathrm{s}^{-1}$ & $\mathrm{E}_{\mathrm{i}}, \mathrm{kcal} / \mathrm{mol}$ \\
\hline 1 & 0.1 & 30 \\
\hline 2 & 0.2 & 15 \\
\hline 3 & $0.25 \cdot 10^{-4}$ & 20 \\
\hline 4 & $1.0 \cdot 10^{-4}$ & 5 \\
\hline
\end{tabular}

\subsection{Spatial Regulation in a Dual-Reactor System}

In the dual-reactor system the reactant is fed only into reactor 1 operating at the high temperature level $\mathrm{T}^{\prime}$ (Fig. 4). The second reactor operating at the lower temperature $\mathrm{T}^{\prime \prime}$ serves as catalyst "regenerator", in which $\mathrm{S}_{2}$ sites are transformed into $S_{1}$ species. The catalyst is circulated permanently between the two reactors and is always in an unsteady state with respect to the time-invariant reaction conditions.

Perfect gas and solid mixing is assumed in both reactors. Under steady-state conditions the following mass balances are obtained:

$\mathrm{C}_{\mathrm{A}}^{\mathrm{o}}-\mathrm{C}_{\mathrm{A}}-\tau^{\prime} \mathrm{a}\left[\mathrm{k}_{1}\left(\mathrm{~T}^{\prime}\right) \mathrm{C}_{\mathrm{A}} \theta^{\prime}+\mathrm{k}_{2}\left(\mathrm{~T}^{\prime}\right) \mathrm{C}_{\mathrm{A}}\left(1-\theta^{\prime}\right)\right]=0$

$\mathrm{u}_{\mathrm{c}}\left(\theta^{\prime \prime}-\theta^{\prime}\right)-\alpha^{\prime}\left[\mathrm{k}_{3}\left(\mathrm{~T}^{\prime}\right) \theta^{\prime}-\mathrm{k}_{4}\left(\mathrm{~T}^{\prime}\right)\left(1-\theta^{\prime}\right)\right]=0$

$\mathrm{u}_{\mathrm{c}}\left(\theta^{\prime}-\theta^{\prime \prime}\right)-\left(1-\alpha^{\prime}\right)\left[\mathrm{k}_{3}\left(\mathrm{~T}^{\prime \prime}\right) \theta^{\prime \prime}-\mathrm{k}_{4}\left(\mathrm{~T}^{\prime \prime}\right)\left(1-\theta^{\prime \prime}\right)\right]=0$

Solving Eqs. (33) and (34) for the concentration of site $S_{1}$ in the two reactors the following relationships are obtained:

$$
\begin{aligned}
\theta^{\prime}= & \left\{\alpha^{\prime} \mathrm{k}_{4}\left(\mathrm{~T}^{\prime}\right)\left[\mathrm{u}_{\mathrm{c}}+\left(1-\alpha^{\prime}\right)\left[\mathrm{k}_{3}\left(\mathrm{~T}^{\prime \prime}\right)+\mathrm{k}_{4}\left(\mathrm{~T}^{\prime \prime}\right)\right]\right]\right. \\
& \left.-\mathrm{u}_{\mathrm{c}}\left(1-\alpha^{\prime}\right) \mathrm{k}_{4}\left(\mathrm{~T}^{\prime \prime}\right)\right\} / \sigma \\
\theta^{\prime \prime}= & \left\{\left(1-\alpha^{\prime}\right) \mathrm{k}_{4}\left(\mathrm{~T}^{\prime \prime}\right)\left[\mathrm{u}_{\mathrm{c}}+\alpha^{\prime}\left[\mathrm{k}_{3}\left(\mathrm{~T}^{\prime}\right)+\mathrm{k}_{4}\left(\mathrm{~T}^{\prime}\right)\right]\right]\right. \\
& \left.-\mathrm{u}_{\mathrm{c}} \alpha^{\prime} \mathrm{k}_{4}\left(\mathrm{~T}^{\prime}\right)\right\} / \sigma
\end{aligned}
$$

with

$\sigma=-\mathrm{u}_{\mathrm{c}}^{2}+\left\{\mathrm{u}_{\mathrm{c}}+\alpha^{\prime}\left[\mathrm{k}_{3}\left(\mathrm{~T}^{\prime}\right)+\mathrm{k}_{4}\left(\mathrm{~T}^{\prime}\right)\right]\right\}\left\{\mathrm{u}_{\mathrm{c}}+\left(1-\alpha^{\prime}\right)\left[\mathrm{k}_{3}\left(\mathrm{~T}^{\prime \prime}\right)+\right.\right.$ $\left.\left.\mathrm{k}_{4}\left(\mathrm{~T}^{\prime \prime}\right)\right]\right\}$.

The reaction selectivity towards the desired product at the outlet of reactor 1 can be determined from Eq. (28), with $\theta^{\prime}$ given by Eq. (35).

$\mathrm{S}_{\mathrm{B}}=\frac{\mathrm{r}_{1}}{\mathrm{r}_{1}+\mathrm{r}_{2}}=\frac{1}{1+\frac{\mathrm{k}_{2}}{\mathrm{k}_{1}}\left(\frac{1}{\theta^{\prime}}-1\right)}$

To get high selectivities, the concentration of $\mathrm{S}_{1}\left(\theta^{\prime}\right)$ and the temperature $\left(\mathrm{T}^{\prime}\right)$ in the first reactor must be high. As the transformation of $S_{1}$ in $S_{2}$ is favored at elevated temperatures, the "regenerator" has to work at lower temperatures.

In Fig. 9 the selectivity $S$ and the surface concentration of $S_{1}$ $\theta^{\prime}, \theta^{\prime \prime}$ in the first and second reactor are plotted against the circulation rate $\mathrm{u}_{\mathrm{c}}$ for a given set of temperatures and volume ratio. With increasing $u_{c}$ the concentration of $S_{1}$ in the first reactor $\left(\theta^{\prime}\right)$ and the obtainable selectivity increases, whereas $\theta^{\prime \prime}$ decreases. The most important selectivity rise is observed at low circulation rates: starting at the steady-state selectivity of $\mathrm{S}_{\mathrm{s}}=66.7 \%$ a selectivity of $85.3 \%$ is obtained for $\mathrm{u}_{\mathrm{c}}=1 \mathrm{~h}^{-1}$. At very high circulation rates $\left(\mathrm{u}_{\mathrm{c}}==>\infty\right)$ the surface concentrations in both reactors become identical $\left(\theta^{\prime}=\theta^{\prime \prime}\right)$ and the selectivity approaches the maximal value of $\mathrm{S}_{\mathrm{lim}}=87.8 \%$. The obtainable selectivity increase is therefore ca. $31 \%$.

The final surface concentration $\left(\theta_{\lim }=\theta^{\prime}=\theta^{\prime \prime}\right)$ at $\mathrm{u}_{\mathrm{c}}==>\infty$ depends on the rate constants $\mathrm{k}_{3}, \mathrm{k}_{4}$ and the volume fraction $\alpha^{\prime}$ :

$\theta_{\lim }=\left[\alpha^{\prime} \mathrm{k}_{4}\left(\mathrm{~T}^{\prime}\right)+\alpha^{\prime \prime} \mathrm{k}_{4}\left(\mathrm{~T}^{\prime \prime}\right)\right]\left\{\alpha^{\prime}\left[\mathrm{k}_{3}\left(\mathrm{~T}^{\prime}\right)\right.\right.$

$\left.\left.+\mathrm{k}_{4}\left(\mathrm{~T}^{\prime}\right)\right]+\alpha^{\prime \prime}\left[\mathrm{k}_{3}\left(\mathrm{~T}^{\prime \prime}\right)+\mathrm{k}_{4}\left(\mathrm{~T}^{\prime \prime}\right)\right]\right\}^{-1}$

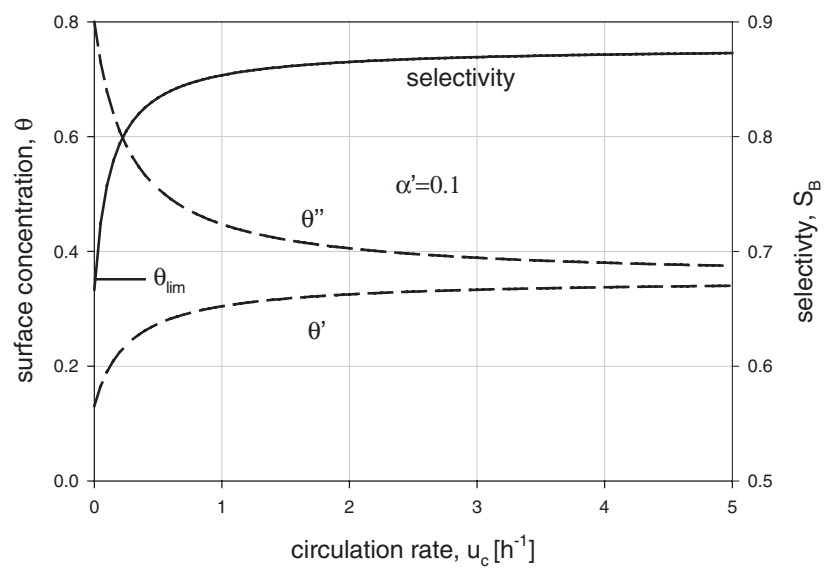

Figure 9. Dependence of selectivity $\left(\mathrm{S}_{\mathrm{B}}\right)$ and concentration of active sites in the first $\left(\theta^{\prime}\right)$ and in the second $\left(\theta^{\prime \prime}\right)$ reactor as function of catalyst circulation rate $\left(\mathrm{u}_{\mathrm{c}}\right) ;$ Model II. 


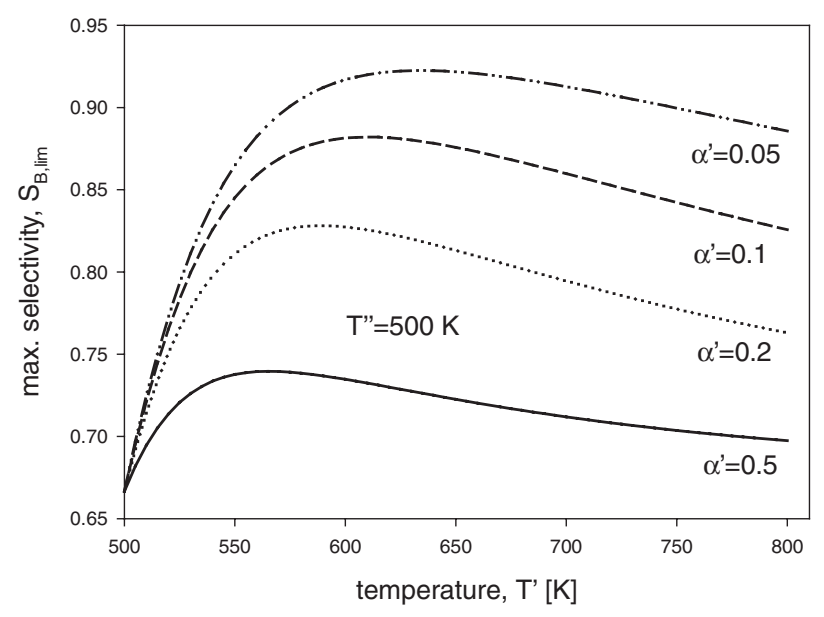

Figure 10. Influence of temperature in the first reactor and ratio of the catalyst volumes on the selectivity $\left(\mathrm{S}_{\mathrm{B}}\right)$. Model II. $T^{\prime \prime}=500 \mathrm{~K}, u_{\mathrm{c}} \rightarrow \infty$.

By substituting Eq. (37) into Eq. (28b), the maximal selectivity can be determined:

$\mathrm{S}_{\mathrm{B}, \lim }=\left(1+\frac{\mathrm{k}_{2}\left(\mathrm{~T}^{\prime}\right) \mathrm{k}_{3}\left(\mathrm{~T}^{\prime}\right)}{\mathrm{k}_{1}\left(\mathrm{~T}^{\prime}\right) \mathrm{k}_{4}\left(\mathrm{~T}^{\prime}\right)} \varphi\right)^{-1}$
with $\varphi=\left(1+\frac{\alpha^{\prime \prime} \mathrm{k}_{3}\left(T^{\prime \prime}\right)}{\alpha^{\prime} \mathrm{k}_{3}\left(T^{\prime}\right)}\right)\left(1+\frac{\alpha^{\prime \prime} \mathrm{k}_{4}\left(T^{\prime \prime}\right)}{\alpha^{\prime} \mathrm{k}_{4}\left(T^{\prime}\right)}\right)^{-1}$

where $\alpha^{\prime \prime}=1-\alpha^{\prime}$.

For a given set of kinetic parameters, the maximal selectivity depends on the factor $\phi$, which is a function of $\alpha^{\prime}$ and the ratio of the rate constants at the different temperature levels in the two reactors $\left[\mathrm{k}_{3}\left(\mathrm{~T}^{\prime}\right) / \mathrm{k}_{3}\left(\mathrm{~T}^{\prime \prime}\right), \mathrm{k}_{4}\left(\mathrm{~T}^{\prime} / \mathrm{k}_{4}\left(\mathrm{~T}^{\prime \prime}\right)\right]\right.$.

The influence of these two factors is shown in Fig. 10. For a given temperature $T^{\prime \prime}$ and volume fraction the selectivity $S_{\text {lim }}$ as function of temperature $T^{\prime}$ passes through a maximum, which is dependent on $\alpha^{\prime}$. With decreasing volume of the first reactor $\left(\alpha^{\prime}\right)$ the optimal temperature and the maximum selectivity increases. For $\alpha^{\prime}==>0$ the selectivity tends to $\mathrm{S}_{\lim }$ $==>1$. But as the performance of the dual system diminishes with $\alpha^{\prime}$, a compromise between selectivity and productivity must be found.

\section{Conclusion}

The reaction unsteady-state performance controlled by (i) periodic operation of reactor and (ii) spatial regulation in a dual-reactor system was studied on the base of two different types of kinetic models: (I) with blocking one of the active sites by reactant and (II) with transformation active sites one into another under influence of temperature. The main purpose was to investigate the possibility of getting mean reaction rate or selectivity towards the target product under unsteady state higher than the optimal steady-state values.

The influence of various parameters like concentrations of reactant, cycle split, period of forced oscillations, temperature of reactors, circulation number and ratio of catalyst volumes in reactors was investigated. It was shown that under periodic operations and in dual-reactor system the model I predicts mean reaction rates, which can exceed approximately twice the steady-state value.

The optimization of the above mentioned parameters on the base model II allowed to increase the selectivity towards the desired product from $66.7 \%$ up to $86-90 \%$. The main parameters influencing the selectivity were the reaction temperature, the amount of the catalyst in each reactor and the rate of the catalyst circulation between two reactors. The rate of circulation is dictated mostly by the rate of active sites transformation.

\section{Acknowledgements}

The authors gratefully acknowledge the funding from the European Commission under the Inco-Copernicus Programme (grant N IC15-CT97-0709) and the Swiss National Science Foundation. The work of S. I. Reshetnikov and E. A. Ivanov has been also supported by the Russian Foundation for Basic Research (grant 01-03-32790).

Received: June 26, 2002 [CET 1640]

\section{Symbols used}

\begin{tabular}{|c|c|c|}
\hline $\mathrm{a}$ & & coefficient of a catalyst activity \\
\hline $\mathrm{C}_{\mathrm{A}}$ & & molar fraction of reactant $\mathrm{A}$ in a reactor \\
\hline $\mathrm{E}_{\mathrm{i}}$ & & activation energies (Tab. 2) \\
\hline $\mathrm{k}_{\mathrm{i}}$ & & rate constant \\
\hline $\mathrm{K}_{2}$ & & equilibrium constant, $\mathrm{K}_{2}=k_{2} / k_{-2}$ \\
\hline Q & {$\left[\mathrm{m}^{3} \mathrm{c}^{-1}\right]$} & valumetric flow rate of a catalyst \\
\hline $\mathrm{T}$ & {$[\mathrm{s}]$} & time \\
\hline $\mathrm{V}_{\mathrm{i}}$ & {$\left[\mathrm{m}^{3}\right]$} & catalyst volume in the i-th reactor \\
\hline & {$\left[\mathrm{s}^{-1}\right]$} & catalyst circulation number \\
\hline & {$\left[\mathrm{s}^{-1}\right]$} & reaction rate of steps \\
\hline $\mathrm{R}, \overline{\mathrm{R}}$ & {$\left[\mathrm{s}^{-1}\right]$} & $\begin{array}{l}\text { reaction rate and averaged reaction } \\
\text { rate respectively }\end{array}$ \\
\hline $\mathrm{R}_{\mathrm{S}}$ & & $\begin{array}{l}\text { steady-state rate of reaction for } \\
\text { concentration } \mathrm{C}_{\mathrm{A}}, \mathrm{s}^{-1}\end{array}$ \\
\hline
\end{tabular}

\section{Greek symbols}

$\alpha^{\prime}$

fraction of the catalyst in the first reactor; $=\mathrm{V}_{1} /\left(\mathrm{V}_{1}+\mathrm{V}_{2}\right)$ $\begin{array}{lll}\gamma & & \text { period split } \\ \tau & {[\mathrm{s}]} & \text { period time }\end{array}$ $\tau^{\prime} \quad[\mathrm{s}] \quad$ contact time $\tau_{\mathrm{R}} \quad[\mathrm{s}]$ $\theta_{\mathrm{i}}$ relaxation time of catalysis $=\left[\mathrm{AS}_{\mathrm{i}}\right] /\left(\left[\mathrm{S}_{\mathrm{i}}\right]+\left[\mathrm{AS}_{\mathrm{i}}\right]\right)$ for the first model $(i=1,2)$ $=\left[\mathrm{S}_{1}\right] /\left(\left[\mathrm{S}_{1}\right]+\left[\mathrm{S}_{2}\right]\right)$ for the second model 
$\theta_{\mathrm{S}}, \theta_{1 \mathrm{~S}}, \theta_{2 \mathrm{~S}}$

$\theta_{01}$

dimensionless steady-state concentrations of surface sites $\theta, \theta_{1}, \theta_{2}$ dimensionless concentrations of $\theta_{1}$ in Eq. (4)

\section{Superscripts}

11

corresponds to the first part of periods (or the first reactor) corresponds to the second part of periods (or the second reactor)

\section{References}

[1] A. Renken, Int. Chem. Eng. 1984, 24, 22.

[2] Y. S. Matros, Catalytic Processes under Unsteady-State Conditions, Elsevier, Amsterdam 1989.

[3] P. L. Silveston, R. R. Hudgins, A. Renken, Catal. Today 1995, 25, 91.
[4] P. L. Silveston, Composition Modulation of Catalytic Reactors, Gordon and Breach Science Publishers, Amsterdam 1998

[5] S. Golay, R. Doepper, A. Renken, Chem. Eng. Sci. 1998, 54, 4469.

[6] A. Rouge, A. Renken, in Reaction Kinetics and the Development and Operation of Catalytic Processes, Vol. 133 (Eds: G. F. Froment, K. C. Waugh), Elsevier Science B. V., Amsterdam 2001, 239.

[7] A. Rouge, B. Spoetzl, K. Gebauer, R. Schenk, A. Renken, Chem. Eng. Sci. 2001, 56, 1419 .

[8] R. M. Contractor, A. W. Sleight, Catal. Today 1988, 1, 587.

[9] H. Y. Pan, R. G. Minet, S. W. Benson, T. T. Tsotsis, Ind. Eng. Chem. Res. 1994, 33, 2996.

[10] Y. S. Matros, Can. J. Chem. Eng. Sci. 1996, 74, 566.

[11] K. Klusacek, R. R. Hudgins, P. L. Silveston, Can. J. Chem. Eng. Sci. 1989, 67, 516.

[12] F. J. R. Van Neer, A. J. Kodde, H. Den Uil, A. Bliek, Can. J. Chem. Eng. Sci. 1996, 74, 664 .

[13] U. Pannek, L. Mleczko, Chem. Eng. Technol. 1998, 21, 811.

[14] J. Koubek, J. Pasek, V. Ruzicka, in New Horizons in Catalysis, ElsevierKodansha, Amsterdam-Tokyo 1980, 853.

[15] J. Thullie, A. Renken, Chem. Eng. Sci. 1991, 46, 1083

[16] J. Thullie, A. Renken, Chem. Eng. Sci. 1993, 48, 3921.

[17] S. I. Reshetnikov, A. A. Ivanov, V. P. Gaevoi, I. Sadovskaja, L. G. Pinaeva, B. S. Balzinimaev, Proceedings of CHEMREACTOR-13, Vol. 2 , Boreskov Institute of Catalysis, Novosibirsk 1996, 5. 